\title{
Just and safe housing for informal settlers in the developing world
}

\author{
J. Cuadra, M. Samples, R. Brower \& J. Dilling \\ Florida State University, USA
}

\begin{abstract}
The risk of disaster is increasing globally, particularly in under-developed or developing countries, due to population pressure and poverty. This risk is elevated where informal and non-permanent settlement housing is prevalent as these communities are caught up in a vicious repeat cycle of destruction and loss of life due to their location in high risk areas. In our study, we focus principally on the actions of informal settlers who inhabit areas that leave them vulnerable to disasters and, the often exasperating efforts of government leaders attempting to relocate them to safer settings. We believe that governments (the state) and communities often have difficulty finding a point of agreement because they have varying rationales on what is "just" and what constitutes safe and appropriate housing. These perspectives are founded on different forms of judgment: one based on scientific facts and politics and one on social, emotive and aesthetic experiences. Practitioners often fail at solving these difficult problems because during dialogues people tend to only communicate positions rather than interests. A better understanding of the feelings and emotions of those affected could lead to more accurate transmission of their own positions and interests to others. In this study, we attempt first to clarify the origins of the conflicts between both perspectives using relevant literature on the topic; to later make use of preliminary data from our field work in the Philippines to serve as an example of the benefits of a careful study of the cultural, social, economic, and political factors and interactive dynamics that helps explain the way people decide where to live. The collection and analysis of such data for different case studies should contribute towards a better understanding of the individuals at risk and formulation of more effective disaster reduction strategies.
\end{abstract}

Keywords: high risk settlements, justice, relocation, community resistance. 


\section{Introduction}

More than a billion people live in marginal and informal settlements, many without access to basic services, and very frequently in high-risk areas. The risk of disaster is increasing globally, particularly in under developed or developing countries, due to population pressure and poverty. This risk is elevated where informal and non-permanent settlement housing is prevalent. Their vulnerability to disaster events is often compounded by a lack of infrastructure, environmental degradation, and increasing challenges exacerbated by climate change and sea level rise. Researchers and local governments are in need of a better understanding of the societal and community dynamics of these groups in order to provide for permanent housing and a place they can call home. The understanding of human settlement vulnerability, when taken together with the underlying factors that create and maintain settlements, is crucial in making settlements more resilient.

\section{Conflict between justice and safety}

In our study we focus principally on the actions of informal settlers who inhabit areas that leave them vulnerable to disasters and, on the other hand, the often exasperating efforts of government leaders attempting to relocate them to safer settings. As scholars dedicated to implementing formal systems to prevent and respond to human calamities we largely share a mindset with the government leaders. On the other hand, we are mindful that people choose to live where they live for many reasons; many of these are deeply embedded. The state and its officials are then faced with the necessity to balance between ensuring safety and providing the informal settlers just treatment. But why should we worry about justice in the context of high-risk settlements? Fainstein [2], in her work on justice in the urban planning context, suggests that, not only governments, but specifically the planning profession, have neglected the needs of the powerless. Currently the critiques of planning and public policy focus on the wrong actions of the centralized decision making process, those that deliberately block the voices of the affected publics. Urban development has a history of inequality and policy implementation that exacerbates the disadvantages suffered by low-income minorities. This is especially true for those living in informal settlements.

Relocation or involuntary resettlement is often deemed the easiest solution to the problem of vulnerable communities. From the state point of view, there are good reasons to do this: to protect vulnerable groups and to reduce fiscal drain resulting from multiple relief and reconstruction efforts. However, in the developing world, relocation by the government is often a failure. The principal reason for this failure is "underweighting the welfare of the population as a criterion for the selection of the relocation site" (Jha [3]). Welfare in this sense is understood as the compilation of factors that create wellness and sustain human settlements beyond economy and geographic location. It is important, therefore, 
that we make a concerted effort to understand the life-world of those on the other side of the equation. We can imagine then that for the informal settler justice means being able to choose where to live. This includes having access to goods and services even if it comes with the probability of suffering the effects of natural phenomena. On the other hand the state perceives justice in this context as the equal opportunity to enjoy safe and stable housing. Fainstein [2] tells us that a general understanding of justice in urban context should be separated from the concept of "good life" since the definition of "good" varies from person to person. Then, she proposes that justice in the urban context consists of actions and outcomes that comply with elements of equity, democracy and diversity. By complying with these three elements of justice we can ensure a fairer process and outcomes for the least advantaged. Informal settlers threatened with relocation perceive state treatment as unjust, whereas state actors believe they are contributing to some extent to a just cause whether the public understands it or not. Scott's [4] perspective reflects how morality and perceptions of justice play into the decisions of informal settlers, who often feel they have a moral right to occupy these properties, since government and societal elites have previously stripped them of traditional communal or usufruct property rights elsewhere.

But communities living in informal settlements are not always defenseless and passive. Organized groups have the potential to influence state legislation. According to Friedmann [5], society is the handy work of the people and the state cannot dominate organized people, at least not for too long. Interestingly communities facing relocation find strength in constant dialogue and collective critical analysis of their situation. Habermassian theories suggest that by use of constant dialogue communities are able to communicate in public arenas, sort out their priorities and decide courses of action (Healey [6]). These public arenas or areas of social interactions such as bars, churches, cafes or markets are an important asset to peasant resistance according to Scott [7] since they represent focal points of autonomous public life.

Faced with imminent relocation, communities are pushed to develop strategies to fight back against state intentions. Scott [8] argues that these acts of resistance and thoughts about resistance are in constant communication; it's a cycle of trial and error by which communities develop over time effective strategies to exert pressure. The case of Latin America is a good example of the slow but steady self-empowerment movement among informal settlers. In the past, informal areas were ignored and bulldozed, but citizen pressures on politicians and public protests have secured them a means for upgrading infrastructure and legalization of their communities (Satterthwaite [9]).

Ideally, governments and the politically powerful should ease the process of adaptation for those being resettled. Also, "it must make sure land is available that is not at risk". Land prices dependable on income lead to communities settling in ill-suited areas (Satterthwaite [9]). In reality, political interests can harm communities; e.g., in developing countries in Latin America, governmental support is provided to neighborhoods sitting in risk areas in exchange for electoral votes. Both electoral seasons and natural disasters represent an 
important window of opportunity not only for policy makers to enact legislation and improve zoning, but also for settlers to demand better conditions and opportunities from the politically powerful.

Fainstein [2] argues that a possible solution for the conflicting concepts of justice and safety is to include urban planners as mediators in the conflict between state and informal settlers so as to bring to public attention certain topics that may affect citizens. This planner would distribute pieces of information crucial to the cause for resistance. This is an advocacy planner. However, this could also be the role of emergency managers. Unfortunately, state officials, urban planners and emergency managers must also comply with norms of ethics and loyalty to the ultimate employer which in most cases is the state. Communities living in informal settlements have strong sentiments on and interest in these causes, having these government officials on their side would be crucial to real social movement. Planners and emergency managers are confronted, then, with the certainty that contribution to these social causes could produce significant outcomes closer to the ideal of justice.

NGOs on the other hand also have the potential to work closely with informal settlers and build participative plans to accommodate their social and economic concerns. Many of these NGOs also possess the advocacy and interpersonal communication skills to negotiate with government leaders and ameliorate their apprehensions as well. We include these NGO actors in the roles of "brokers" and "translators" (Lewis and Mosse [10]). But their activities also reflect significant structural features of their relationships with government leaders and informal communities. That is, NGO actors' positions within networks affect their abilities to shape others' thoughts and actions as some actors are largely under the influence of others and constrained from taking novel actions (Borgatti et al. [11]). In addition, their abilities to shape others' thoughts and negotiate on behalf of informal settlers hinge in part on cultural capital (Bourdieu [12]) and class similarities they share with government officials.

In acknowledging the underlying dynamic of relocation resistance, we do not wish to romanticize these activities. We believe, however, that the underlying sentiment of informal settlers' "moral economy" must be accommodated in any planning that government leaders undertake in working with these settlers. We ought to seek the settlers' sense of moral entitlement in gathering data from them and government's eventual disaster planning must anticipate the practical implications of informal settlers' sentiments.

\section{Opposing rationalities: state and informal settlers}

What is dividing state and informal settlers' perspectives on safety and appropriate living conditions? Friedmann [5] argues that in common language an action is deemed rational when it conforms to certain forms of socially accepted judgment, such as economic efficiency or conforming to socially expected 
behavior. Socially accepted judgment and behavior are susceptible to changes among different countries, cultures, social levels and time periods. Rationality could then potentially be defined differently by certain people and affected by context, culture and social norms.

Let us concentrate on the context of informal settlers and their decisions to reside in areas of demonstrated risk. State officials usually base their rationale on scientific analysis: equating levels of risk by combining vulnerability and hazard exposure. The result of this simple equation provides government officials with a scientifically accepted judgment to propose relocation. Unfortunately, this is a strictly scientifically accepted judgment not always compliant with socially accepted judgment. Conversely, the community's reason for living in such areas belongs to a different category of judgment, one characterized by considerable emotional and social content.

It could be argued that the rationale applied by the state is narrowly constructed around scientific analysis and the specific political pressures on government actors to take decisive action. Similarly, informal communities have constructed narrow realities around their own everyday social experiences. The state rationale may fail to comprehend complex situations as it tends to simplify real world scenarios. Forester [13] tells us about some of the failed assumptions from the state:

- overall comprehension of the problem,

- possession of the definite list of possible alternatives to consider,

- absolute understanding of the potential consequences of each alternative,

- full understanding of the values and preferences of citizens,

- adequate time, skills and resources to solve the problem.

The community rationale is not exempt from distortions either. Socially, emotionally or aesthetically generated knowledge is subject to constant change and is also difficult to measure for comparative purposes. Attaching a numerical value to these qualities is nearly an impossible task. The rationales of members of the informal community may appear similarly illogical from the vantage point of state actors, and these rationales distill easily to a single viewpoint that represents the inhabitants uniformly. Their variability reflects the diverse physical locations of their dwellings, the varieties of informal employment in which they are engaged, their particular family and other social relationships, and the varied daily routines of their family members. Thus, among the residents of the same informal settlement, there may be disagreement about the social and emotional value of various community assets and how much they would be willing to sacrifice to protect these assets. Here, we observe the reason why state and communities do not seem to reach agreement: their rationales are founded on different bases of judgment. It is then as if they were speaking in two different languages, and these languages reflect the particular features of their distinctive social embeddedness (Granovetter [14]). Often practitioners fail to solve difficult problems because during dialogues people tend to only communicate positions rather than interests (Innes and Booher [1]). There is value in finding a common ground of understanding. That might be through expression of interests rather 
than figures and facts, on the one hand, or socially-embedded experiences and emotional attachments, on the other. It is important then to differentiate between the judgment foundations for each perspective.

\section{Exploring informal settlers' rationality}

Why do people choose to live in these areas of demonstrated risk and vulnerability? They may make that choice because of land tenure; social and cultural ties to the community; availability of fertile land and food sources; and access to transportation and commerce. For the urban poor, it is often due to the availability of affordable housing and proximity to livelihood opportunities (Jha [3]). A look back at the history of human civilization is instructive for the reasons people decide to settle in certain areas over others. These early communities were just starting to discover agriculture, wild fruit harvesting, animal domestication and fishing as well as shelter construction techniques. These important advances changed and influenced their relationship with the land they inhabited. By attaching themselves to this new land that provided them with food and shelter the first human settlements embraced a sedentary society. And so, the ideal pattern of settlements arose to include access to food and other materials in commune with others with similar aspirations. Still, today every person needs access to the products of the land with the benefits and services of towns and cities. "The ideal pattern is one which equalizes the opportunities of town life and country life to the maximum extent" (Schumacher [15]).

It is rational to assume that humans will continue to gather around areas with more resources. The consequence of such heavy clusters around resources is increased vulnerability to natural and man-made hazards - the "on-going societal and man-environment relations that prefigure [disaster]" Hewitt [16]. In the past, the amount of damage in cities was reduced because of two factors: 1) the most dangerous sites were avoided and 2) cities were relatively small and less densely populated. Today our cities are larger, leading some communities to occupy high risk areas (Hardoy and Satterthwaite [17]). It follows that those with lower income tend to populate the higher risk areas because of the reduced value of the land and the minimum legal requirements to settle. Informal communities often settle on public land deemed unsuitable for development because of its inherent risk. They often cannot afford to live elsewhere. These sites also lack risk-reducing infrastructure and services, therefore, the inhabitants get less support for reconstruction after a disaster. Large numbers abandon poor rural regions because of the lack of opportunities and the appeal of distant cities. This usually means moving from a rural home to a city slum. Comparatively, at the global level, the gap between the rich and the poor has widened following the path of technological development. It could be assumed that the pattern of settlement is directly affected by the advances in technology and the disappearing trend of middle class dwellers. These forces are pushing people into the big towns and cities directly into the line of danger. 


\subsection{Cultural and emotional attachment to at risk areas}

The place that we call home is not just a point in a geographical setting. Communities develop shared values and shared identity with place (Hewitt [18]). Wellbeing and a sense of comfort can be associated with familiarity with place; disasters destroy that sense of security. Post-disaster survival stories often include reports of unrecognizable surroundings and loneliness. To lose connection with the place where we live means to feel abandoned by the people that form part of our daily lives.

Communities that possess a rich heritage consider it a serious matter to conserve their traditional ways of life even after a disaster. Resettled groups report difficulties in maintaining a traditional way of life and traditions that can be successfully transmitted to the new generations. The Moken people from Thailand argue that after the tsunami that destroyed their houses, their children lost interest in their own language and culture. The elders blame this on the location of the rebuilt community near a road that links them to city areas (Nidhiprabha [19]).

The town of Yungay in Peru is a good example of survivors willing to return to a devastated area. The great earthquake of 1979 followed by an avalanche from Mount Huascaran buried the town. Survivors claimed that they were sons of that devastated land and therefore were accustomed to dying and losing family. These strong remarks caught the attention of researchers like Oliver-Smith [20] and Bode [21]. Oliver-Smith [20] concludes that "The determination of the survivors to found and maintain a new Yungay, albeit one of vastly different appearance, constitutes a refusal to allow part of their identity and their culture to die". Similarly, Bode [21] reported that "it was hoped that the streets, too, could remain in their places and could retain their own names"; survivors also expressed "we would be very sad and confused if streets were called by other names". In his report for the UNISDR, Satterthwaite [9] argues that communities at risk that refuse to relocate have an option to stand up to government policy by developing proposals to show how to survive in such areas. There are cases where the location of a community shapes the way people associate and solve their problems; one can even argue that such conditions stimulate citizen participation and creativity.

\subsection{Economy influencing informal settlers}

Being part of a community not only benefits an individual's inner well-being, but also has powerful effects on the economic aspects of his or her life. Groups with limited resources tend to cluster in groups of self-support surviving by surrounding themselves with helping neighbors and family members. Similarly, disadvantaged groups such as women and the elderly find support in community unity; LaFerrara [22] argues that "people who do not have access to the formal labor market and whose options in the informal market are unattractive can often benefit from pooling resources and working in groups". Several examples in Latin America illustrate that uneducated women and single mothers benefit greatly from associating in small cooperatives which can get funding to start 
micro businesses in either the manufacture or service areas. Thus, it can be inferred that there is a higher chance of alleviating poverty through community associations and housing stability. For these groups, the community or neighborhood is more than a geographical point as it represents a place with higher opportunities for survival. Often, a lack of affordable land near impacted settlements occasion relocation to areas distant to the original settlement where land may be available and less expensive. Relocation on the grounds of potential or eminent danger fails because the new land does not provide similar economic opportunities. Resettlement of people from risky areas should carefully consider the relocation of the livelihoods and the availability of services to support the already existent economic dynamics, since these communities' economy is already extremely delicate.

Given these parallel dynamics; attachment to familiar locations and social embeddedness in local economic opportunities, it is essential that any planning that attempts to move informal settlers from high risk locations must engage the settlers in identifying and accommodating the factors that define their everyday existence.

\section{Informing relocation decision making and alternative strategies}

Disaster mapping and risk evaluations are common activities for researchers and government officials throughout the world. Such data produce reports that create a picture of a certain location or community. Relying on numbers and maps to determine the situation of an at risk settlement is necessary, but may not be sufficient in of by itself. We suggest there should be better efforts in integrating the environmental elements that shape the behavior and identity of a given community with risk mapping and assessment.

Failure to identify such social, cultural, economic and political factors leads to poorly informed decision making and policy. It also undermines the process by which we may reduce or avoid relocation through mitigation or adaptive measures. Furthermore, as discussed above, if such strategies and policies do not comply with the realities of the community there will likely be reasonable opposition and even social unrest during the implementation processes. Our proposition: social, cultural, economic and political factors and interactive dynamics affect the way people decide where to live in spite of risk conditions. The outcome of this study is expected to enrich planning and emergency management efforts in cities with at-risk settlement dilemmas. It is our objective to: identify cultural, social, economic and social factors that influence people's decision of settlement. More specifically, we plan to:

- to determine the factors and social dynamics that determine the population of human settlements and their decision to remain despite implied or confirmed risk,

- to analyze and present information about communities living in at risk settlements, 
- to create a model to inform governmental decision making on relocation and relocation alternatives.

Multiple studies to this day have individually studied human settlement tendencies and social factors shaping communities (Jha [3], Granovetter [14] and Schumacher [15]). But the correlation between the two has received relatively little empirical attention. This study strives to answer the question: what are the processes and factors that determine why communities remain in their settlements in spite of risk? Hewitt [18] proposes that "Geography enters all levels of human organization, the security of persons and ways of life, and our sense of safety are most intimately bound up with the place of residence and the world to which we belong". It can be inferred from this theory, that the relationship between settlement and social, cultural, economic, and political factors is a direct strong one. This study strives to find a link between these factors and the decision to settle and remain in at risk settlements. It is expected that the study of individuals or households will paint an accurate picture of communities sharing the same space. If the above is correct we should expect a list of factors shaping settlements which can be ranked by level of importance. In order to compile these factors we plan a mixed methods approach with up front inductive ethnographic data gathering and analysis.

Population and Sampling: This study is interested particularly in the individual who is part of a community that is living in at risk settlements and who resists relocation. The individual can be further associated with household units in a community; by sampling households this study plans to map the community's overall relocation mindset. The study will also focus on low income communities in scattered settlements, emphasizing the developing world. The research is designed to consist of multiple case studies in which the investigators describe and identify themes and issues. The researchers will analyze data collected through interviews, observations, and documents. Snowball sampling, a purposeful sampling technique, will be used to locate participants for interviews. Ultimately, this multiple case study can inform a theoretical model that seeks to reduce the loss of life in high risk areas.

\section{Pilot project: Philippines}

Barangay Banaba: Municipality of San Mateo, Rizal Province, Philippines.

Population: Is one of 15 San Mateo barangays, had a 2007 population of 20,861.

Description: Barangay Banaba is located in the southwest corner of San Mateo and is bounded by the Marikina and Nangka Rivers. A few of the homes in these settlements are built from strong materials, but most are built from light or salvaged materials. The rivers, which have flooded the settlements several times in recent years, pose the most significant threat to these settlers and their homes.

Initial Findings: The initial field work in the Philippines showed that informal communities in San Mateo often settle on public land deemed unsuitable for development because of its inherent risk; the inhabitants typically 
cannot afford to live elsewhere. Many have abandoned poor rural regions that lack opportunities for the appeal of distant cities. Our informants suggest that these urban poor resist relocation because their lives, however dismal, are built around informal economies near their slum settlements. Some of them describe results from prior re-settlement programs in which the settlers discover that relocation sites lack these economic opportunities, and they promptly return to the same or similar urban slums.

Under the media spotlight following disasters, government leaders often want to be seen taking definitive action. Following extensive flooding and numerous resultant drownings in Manila in August 2012, for example, public officials drew special attention to those living in creeks and along rivers because "they serve as obstructions to the easy flow of water" (Villas [23]). In this account informal settlers are no longer vulnerable casualties of the flooding: they are its culprits. Therefore, orders came from cabinet officials to begin clearing 125,000 informal settlers and relocating them to other government designated sites. The administration initiated an embarrassing backtrack soon afterward when it was revealed that several designated relocation sites had themselves been inundated.

Our recent field evidence suggests, moreover, that despite good intentions, the top-down plans of government agencies are often built around simplistic monetary incentives that proved unsuccessful in the past. Having studied informal settlements in situ we observe that these plans seriously underestimate the social factors - family, neighbors, informal economic networks, daily routines of family members - that guide the everyday lives of informal settler families.

\section{Summary}

In this, and our subsequent field studies, we seek to identify broader and deeper relationships between human settlements and the willingness to deal with risk. We believe that the findings of our study and our refined instrument will be eminently useful to inform governmental post-or pre-disaster relocation or alternative strategies for mitigating the risks to informal settlements. We are convinced that a complex array of individual, community, and socio-economic factors underlie the sometimes fatal decisions of informal settlers to remain in risk-prone locations. By identifying and ordering this set of factors and the ways they interact, it is possible to inform and enrich government policy making and overall disaster risk reduction efforts. Improved policy making of this type saves lives and fosters cooperative relations between members of the community and those charged with overseeing their wellbeing.

\section{References}

[1] Innes, J. \& Booher, D., Planning with Complexity. An introduction to collaborative rationality for public policy, First Edition. Routledge: New York, pp. 89-117, 2010. 
[2] Fainstein, S., The Just City, Cornell University Press Sage House: Ithaca and London, USA, pp. 5-86, 2010.

[3] Jha, A. K., (ed). Safer Homes, Stronger Communities: A Handbook for Reconstructing after Disasters, Global Facility for Disaster Reduction and Recovery (GFDRR). The World Bank: Washington DC, 2010.

[4] Scott, J. C., The moral economy of the peasant: Rebellion and subsistence in Southeast Asia, Yale University Press: New Haven, CT, pp. 157-230, 1976.

[5] Friedmann, J., Planning in the Public Domain: From Knowledge to Action. Princeton University Press: Princeton New Jersey, pp. 19, 220-284, 1987.

[6] Healey, P., Collaborative Planning: shaping places in fragmented societies. 2nd Edition Palgrave Macmillan: New York, pp. 49-62, 2006.

[7] Scott, J., Seeing Like a State: How Certain Schemes to Improve the Human Condition Have Failed. Yale University Press: New Haven, CT, pp. 214-455, 1998.

[8] Scott, J. C., Weapons of the weak: Everyday forms of peasant resistance. Yale University Press: New Haven, CT, pp. 16-38, 1985.

[9] Satterthwaite, D., What Role for Low-income Communities in Urban Areas in Disaster Risk Reduction? Global Assessment Report on Disaster Risk Reduction, UNISDR: London, pp. 1-48, 2011.

[10] Lewis, D. \& Mosse, D., (eds.) Development brokers and translators: The ethnography of aid and agencies. Kumarian Press: Bloomfield, CT, 2006.

[11] Borgatti, S. P., Mehra, A., Brass, D. J., \& Labianca, G., Network analysis in the social sciences, Science Volume 323, pp. 892-895, 2009.

[12] Bourdieu, P., The forms of capital. In J. G. Richardson, (ed.) The handbook of theory and research in the sociology of education, Greenwood Press: New York, pp. 241-258, 1986.

[13] Forester, J., Planning in the Face of Power. University of California Press: Berkley, Los Angeles, London, pp. 48-64, 1989.

[14] Granovetter, M. S., Economic action and social structure: The problem of embeddedness, American Journal of Sociology, Vol.91, pp. 481-510, 1985.

[15] Schumacher, E. F., Patterns of Human Settlements. Springer: AMBIO Vol. 5, No. 3, pp. 91-97, 1976.

[16] Hewitt, K., (ed.), Interpretations of Calamity: from the viewpoint of human ecology, The Risk and Hazards Series 1, Allen \& Unwin Publishing: USA, pp. 20-27, 1983.

[17] Hardoy, J. E., \& Satterthwaite, D., Squatter citizen: life in the urban third world. Earthscan Publications: London, 1989.

[18] Hewitt, K., Regions at Risk. A geographical introduction to disasters. Addison Wesley Longman: USA, 1997.

[19] Nidhiprabha, B., Adjustment and Recovery in Thailand Two Years after the Tsunami, The Asian Development Bank Institute, Discussion paper No.72 :Tokyo, Japan, pp. 22-37, 2007. 
[20] Oliver-Smith, A. S., The martyred city: death and rebirth in the Andes, 2nd edition. Waveland press: Prospect Heights, IL, pp. 5-27, 1986.

[21] Bode, B., No bells to toll: destruction and creation in the Andes, $1^{\text {st }}$ Edition Scribners: New York, pp. 169-237, 1990.

[22] LaFerrara, E., Self-help groups and income generation in the Informal Settlements of Nairobi, Journal of African Economies, pp. 61-89, 2002.

[23] Villas, A. L. T., Robredo: Act on informal settlers. News article: Tempo.com. August 17, 2012. Retrieved from: http://www.tempo.com. $\mathrm{ph} / 2012 /$ robredo-act-on-informal-settlers/. 